\title{
JC virus existence in Chinese gastrointestinal carcinomas
}

\author{
JIAN-PING WANG $^{1 *}$, ZUO-ZHOU WANG $^{1 *}$, YU-SHUANG ZHENG ${ }^{1}$, PU XIA ${ }^{1}$, \\ XIANG-HONG YANG ${ }^{2}$, YUN-PENG LIU ${ }^{3}$, YASUO TAKANO ${ }^{3}$ and HUA-CHUAN ZHENG ${ }^{1}$ \\ ${ }^{1}$ Department of Biochemistry and Molecular Biology, Institute of Pathology and Physiology,
} College of Basic Medicine, China Medical University; ${ }^{2}$ Division of Pathology, The Affiliated Shengjing Hospital of China Medical University; ${ }^{3}$ Department of Internal Oncology, The First Affiliated Hospital of China Medical University, Shenyang 110001, P.R. China; ${ }^{4}$ Clinical Research Institute, Kanagawa Cancer Center, Yohohama 241-0815, Japan

Received June 20, 2011; Accepted December 16, 2011

DOI: $10.3892 / \mathrm{ol} .2012 .627$

\begin{abstract}
The John Cunningham virus (JCV) infects a large proportion of the population worldwide and may cause progressive multifocal leukoencephalopathy upon immunodeficiency. Recent reports provided evidence of its oncogenetic role in malignancies. In this study, JCV was examined by targeting $\mathrm{T}$ antigen, viral protein and agnoprotein in paraffin-embedded or frozen gastrointestinal carcinomas and paired non-neoplastic mucosa (NNM) samples by nested-PCR followed by Southern blot analysis. In addition, the expression of JCV $\mathrm{T}$ antigen, ki-67, caspase-3, p53, Rb and $\beta$-catenin was studied by immunohistochemistry on tissue microarrays. The positive rate of JCV T antigen was higher in paraffin-embedded gastrointestinal carcinomas compared to adjacent NNM by nested-PCR followed by Southern blot analysis (36.9 vs. 16.9\%, P<0.05), while there was no difference in other viral oncogenes regardless of whether they were paraffin-embedded or frozen samples. Immunohistochemically, $\mathrm{T}$ antigen was detectable in $9.6 \%$ $(13 / 135)$ of carcinoma cases, which was higher than its positive rate in NNM $(0.8 \%, 1 / 126, \mathrm{P}<0.01)$. However, the genomic JCV DNA existence or its T antigen expression was not correlated with age, gender, tumor size, histological types, lymph node metastasis, expression of ki-67, caspase-3, p53, Rb and $\beta$-catenin of gastric carcinomas ( $\mathrm{P}>0.05)$. In conlusion, JCV T antigen may be involved in gastrointestinal carcinogenesis as an oncogene in China.
\end{abstract}

Correspondence to: Professor Hua-Chuan Zheng, Department of Biochemistry and Molecular Biology, Institute of Pathology and Physiology, College of Basic Medicine, China Medical University, Shenyang 110001, P.R. China

E-mail: zheng_huachuan@hotmail.com

*Contributed equally

Key words: John Cunningham virus, gastrointestinal carcinomas, carcinogenesis

\section{Introduction}

The John Cunningham virus (JCV) constitutes a family of polyoma viruses, which are non-enveloped, have icosahedral capsids and contain small, circular, double-stranded DNA genomes. These viruses feature early and late coding regions, whose transcription is initiated in opposite directions by an interposed transcription control region. The early region is alternatively spliced to produce small $t$ antigen and large T antigen, a large phosphoprotein that binds to the viral replication region to promote double helix unwinding and recruitment of cell proteins that are required for DNA synthesis. The late region encodes the capsid structural proteins VP1, VP2 and VP3 due to alternative splicing and the small regulatory element known as agnoprotein. Viral proteins (VP) are essential for assembly with viral DNA to form virions $(1,2)$.

Serological studies have indicated asymptomatic JCV infection in approximately $90 \%$ of the adult population. As JCV replication is restricted to glial and lymphoid cells, which contain the JCV transcriptional factors, the virus enters through tonsillar stromal tissue and persists in a quiescent state in the kidney and lymphoid tissue during latency. However, it may be activated under immunosuppressive conditions, leading to the lethal demyelinating disease, progressive multifocal leukoencephalopathy (PML). JCV infection is initiated with binding to JCV-sensitive cell surfaces. Additionally, JCV capsids undergo endocytosis and are transported to the nucleus where the viral DNA is uncoated and the early region begins to be transcribed. Under permissive infection, replication of viral DNA may result in lytic infection with viral amplification, but in non-permissive cells not allowing viral replication, abortive infection or cell transformation is the result (1-6).

JCV is capable of transforming cells, as manifested by distinct phenotypic and morphological changes, such as growth in agar, rapid division, prolongation of the life span, enhanced production of plasminogen activator, anchoragedependent growth, unstable multicentric chromosomes, centric and acentric rings and the ability to form dense foci in culture (7). Intravenous or intracranial inoculation of JCV into experimental animals has been found to cause astrocytomas, glioblastomas, neuroblastomas and medulloblastomas (1). In addition, transgenic mice expressing the JCV T antigen exhibit 
a $50 \%$ incidence of pituitary adenomas by 1 year of age and some of the mice develop malignant peripheral nerve sheath tumors $(1,8)$. In recent years, the presence of JCV has been suggested to correlate with various types of human neoplasms, including tongue, pharyngeal, gastric, esophageal, colorectal, anal and prostatic cancer, brain tumors and lung carcinomas B (9-21). In our laboratory, the transgenic model of lens tumors induced by JCV $\mathrm{T}$ antigen was previously established for the first time (22). These reports indicate that JCV plays a direct role in human tumorigenesis as an oncovirus.

Molecular mechanisms underlying oncogenesis by JCV may center on its encoded products, T antigen, VP and agnoprotein. The JCV T antigen serves as an ATPase, helicase and polymerase, and orchestrates the assembly and function of cell proteins such as replication protein A and DNA polymerase- $\alpha$. It may also inactivate p53 and members of the pRb family, and deregulate the Wnt signaling pathway to promote uncontrolled proliferation and immortal survival. The induction of structural chromosome aberrations and genomic instability has been described (1-3,6,7). It was found that T antigen inhibited AP2 binding to an AP2 site in the BAG3 promoter, resulting in downregulation of the BAG3 promoter expression and subsequent apoptotic inhibition, since BAG3 functions as a molecular co-chaperone through its interaction with Hsc70/Hsp70 and is capable of initiating apoptosis (23). Reviriego-Mendoza et al (24) have demonstrated that JCV large T antigen binds the F-box proteins $\beta$-transducin-repeat containing protein-1 and $-2(\beta \operatorname{TrCP} 1 / 2)$ and disrupts further proteasomal degradation of $\beta$-catenin. JCV T antigen expression in CRC associates with a metastatic phenotype, which may partly be mediated through the AKT/MAPK signaling pathway.

Despite a worldwide decline in its incidence and mortality since the second half of the 20th century, gastric carcinoma still ranks as the fourth most common and the second most frequent cause of mortality from cancer (25). Colorectal carcinoma is one of the most common types of cancer in the world, accounting for almost $10 \%$ of all new cases of cancer. These cancers continue to be a major health concern, although sophisticated diagnostic and surgical techniques are widely applied in clinical practice (26). JCV has been found in high concentrations in urban sewage worldwide and is closely linked to gastrointestinal carcinogenesis, leading some investigators to suspect contaminated drinking water as a typical route of infection (27). However, there is a lack in the evidence regarding the correlation between JCV existence and gastrointestinal carcinogenesis in China. Therefore, we employed nested PCR and Southern blotting to detect JCV genomic DNA in the frozen and paraffin-embedded samples of Chinese gastric and colorectal carcinomas. Additionally, we aimed to clarify the pathobiological features of JCV-related gastrointestinal carcinomas.

\section{Materials and methods}

Subjects. Formalin-fixed and paraffin-embedded gastric and colorectal carcinoma $(n=40,43)$ and adjacent non-neoplastic mucosa (NNM) $(n=42,23)$ were collected from surgical materials in Shengjing Hospital, China Medical University after obtaining permission from the patients or their relatives. Frozen gastric $(n=22)$ and colorectal $(n=18)$ carcinomas and matched
NNM were also collected here. The Ethics Committee of the Hospital gave approval for the genetic experiments restricted to $\mathrm{JCV}$.

DNA extraction and checking. Paraffin-embedded tissues were sectioned at $10 \mu \mathrm{m}$ and lesions were microdissected with reference to the hematoxylin and eosin (HE) staining of consecutive sections and subjected to deparaffinization. DNA was extracted from cell lines and the deparaffinized samples by standard proteinase $\mathrm{K}$ digestion and phenol/chloroform extraction. The DNA samples were amplified using $\beta$-globin primers; sense: 5'-ACACAACTGTGTTCACTAGC-3' and anti-sense: 5'-GTCTCCTTAAACCTGTCTTG-3' (175 bp) by 30 cycles of denaturation at $95^{\circ} \mathrm{C}$ for $30 \mathrm{sec}$, annealing at $55^{\circ} \mathrm{C}$ for $30 \mathrm{sec}$, and extension at $72^{\circ} \mathrm{C}$ for $30 \mathrm{sec}$ to confirm its integrity.

Nested PCR. PCR amplification was performed using three individual sets of primers for T-antigen: $\mathrm{T} 1$ and T2 (nucleotides 3049-3069 of the Mad-1 strain, 5'-TGG CCTGTAAAGTTCTAGGCA-3' and 3229-3207, 5'-GCAGAG TCAAGGGATTTACCTTC-3', respectively), which amplify sequences in the NH2-terminal region of the JCV T-antigen were used for the first PCR, whereas T1 and T3 (nucleotides 31933171, 5'-AGCAACCTTGATTGCTTAAGAGA-3') were used for the second PCR (145 bp). For the VP capsid gene sequence, VP1 and VP2 (nucleotides 1828-1848, 5'-TGTGCACTC TAATGGGCAAGC-3' and 2019-39, 5'-CTAGGTACGCCT TGTGCTCTG-3', respectively) were used for the first PCR, followed by VP1 and VP3 (nucleotides 2004-1982, 5'-GAT TGCACTGTGGCATTCTTTGG-3') for the second PCR (177 bp). Finally, for JCV agnoprotein, AGNO1 and AGNO2 (nucleotides 280-298, 5'-GTCTGCTCAGTCAAACCACTG-3'; and 458-438, 5'-GTTCTTCGCCAGCTGTCAC-3', respectively), which amplify a region within the coding region of the JCV agnoprotein, were used for the first PCR and AGNO1 and AGNO3 (nucleotides 395-415, 5'-GCACAGG TGAAGACAGTGTAG-3') were used for the second PCR (64 bp). Reaction mixtures $(25 \mu \mathrm{l})$ contained $0.125 \mu \mathrm{l}$ Takara Ex Taq HS (Takara, Japan) with $2.0 \mathrm{mM} \mathrm{MgCl}_{2}, 2.5 \mu \mathrm{l}$ 10X PCR buffer, $2 \mu \mathrm{l} \mathrm{dNTP}$ mixture, $1 \mu \mathrm{M}$ of each primer set (external primers) and $100 \mathrm{ng}$ of template DNA. PCR conditions were denaturation at $95^{\circ} \mathrm{C}$ for $8 \mathrm{~min}$, followed by 30 cycles of denaturation at $95^{\circ} \mathrm{C}$ for $15 \mathrm{sec}$, annealing for $30 \mathrm{sec}$ and extension at $72^{\circ} \mathrm{C}$ for $30 \mathrm{sec}$. The annealing steps were carried out at temperatures of $55^{\circ} \mathrm{C}$ for the $\mathrm{T}$ antigen primers, $57^{\circ} \mathrm{C}$ for the agnoprotein primers and $54^{\circ} \mathrm{C}$ for the VP primers. As a termination step, the extension time of the last cycle was increased to $7 \mathrm{~min}$. The pBSK-T28 or pBSK-JCV plasmid (28) was used as a positive control. Samples amplified in the absence of template DNA were employed as negative controls. Nested PCR was carried out as the first PCR cycle, using $1 \%$ (volume) of the first PCR product with the internal primers in each case.

Southern blotting. Southern blotting was performed by resolving $10 \mu \mathrm{l}$ of each nested PCR product on $2 \%$ agarose gels stained with ethidium bromide. After gels were denatured, neutralized and blotted onto nylon membranes (Hybond N1, Amersham, Germany), hybridization was performed using $20 \mathrm{pmol} / \mathrm{ml}$ of digoxygenin-labeled oligonucleotide probes 

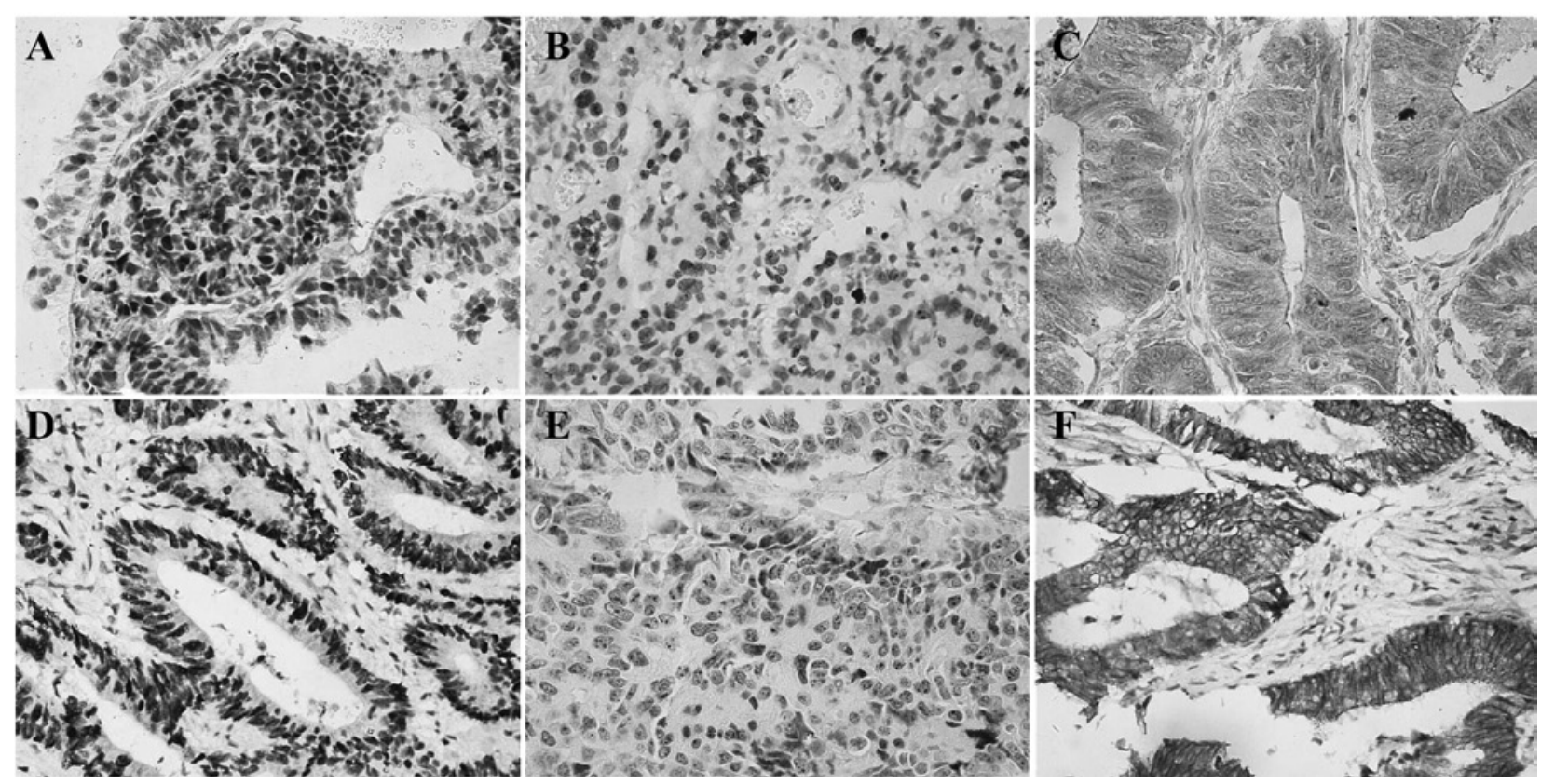

Figure 1. Immunostaining examination in gastrointestinal carcinomas. (A) JCV T antigen was localized in the nucleus of JCI positive control (dark brown), HE staining of a lung carcinoma TMA is shown. (B) The positive expression of ki-67 (nucleus), (C) caspase-3 (cytoplasm) and (D) $\beta$-catenin (membrane, cytoplasm and nucleus) is shown.

(nucleotide 3066-3101 for T antigen 5'-GGCACTGAATATTCA TTCATGGTTACAATTCCAGGT-3'; nucleotide 1872-1891 for VP 5'-AGCCAGTGCAGGGCACCAGC-3' and nucleotide 395-415 for agnoprotein, 5'-AAAGACAGAGACACAGTG GTT-3') at $55^{\circ} \mathrm{C}$ overnight. After washing the membranes with $2 \mathrm{X}$ SSC, $0.1 \%$ sodium dodecyl sulfate (SDS), and $0.1 \mathrm{X}$ SSC and $0.1 \%$ SDS at the same temperature as the hybrid temperature, the membrane was subjected to incubation of the alkaline phosphatase (AP)-labeled anti-digoxygenin antibody for $30 \mathrm{~min}$. Luminescence was detected with X film (Fujifilm, Japan) using a Dig luminescent detection kit for nucleic acids (Boehringer Mannheim, MA, USA).

Tissue microarrays (TMAs). HE-stained sections of 103 lung carcinomas were examined and representative areas of solid tumor were identified for sampling. Two $2 \mathrm{~mm}$-diameter tissue cores per donor block were punched out and transferred to a recipient block holding a maximum of 48 cores using a tissue microarrayer (AZUMAYA KIN-1, Japan). Sections $(4 \mu \mathrm{m})$ were consecutively incised from the recipient blocks and transferred to poly-lysine-coated glass slides. HE staining was performed for confirmation of tumor samples.

Immunohistochemistry. Serial sections were deparaffinized with xylene, dehydrated with alcohol and subjected to antigen retrieval by irradiation in target retrieval solution (TRS, Dako, Carpinteria, CA, USA) for 5 min with a microwave oven (Oriental Rotor Ltd., Tokyo, Japan). Bovine serum albumin (5\%) was then applied for $1 \mathrm{~min}$ to prevent non-specific binding. The sections were incubated with mouse anti-SV40 T antigen (Santa Cruz Biotechnology, Santa Cruz, CA, USA; 1:100), rabbit anti-ki-67 (Dako, USA; 1:25), rabbit anti-p53 (Dako, USA; 1:50), rabbit anti-caspase-3 (Dako, USA; 1:150) or mouse anti-human $\beta$-catenin (BD Biosciences, Transduction
Labs, Franklin Lake, NJ, USA, 1:200) for $15 \mathrm{~min}$, then treated with the anti-mouse or anti-rabbit Envison-PO (Dako, USA) antibody for $15 \mathrm{~min}$. The incubations were performed in a microwave oven with intermittent irradiation, as described previously (29). Following each treatment, the slides were washed with TBST (10 mM Tris- $\mathrm{HCl}, 150 \mathrm{mM} \mathrm{NaCl}, 0.1 \%$ Tween-20) three times for $5 \mathrm{~min}$. The slides were developed for color with 3,3'-diaminobenzidine (DAB) and counterstained with Mayer's hematoxylin. Omission of the primary antibody was used as a negative control.

Evaluation of immunohistochemistry. Immunoreactivity for JCV T antigen, ki-67, p53 and Rb was localized in the nucleus, for caspase- 3 in the cytoplasm, and for $\beta$-catenin in the nucleus, cytoplasm or membrane (Fig. 1). A total of 100 cells were randomly selected and counted from 5 representative fields of each section, blindly, by two independent observers (Wang JP and Zheng HC). The percentages of positive cells in total counted were graded semi-quantitatively using a fourtier scoring system: negative (-), 0-5\%; positive (+), 6-100\%.

Statistical analysis. Statistical analysis was performed using Fisher's test to analyze the positive rates. $\mathrm{P}<0.05$ was considered to be statistically significant. SPSS 10.0 software was employed to analyze all data.

\section{Results}

As shown in Fig. 2, amplification of $\beta$-globin was of high quality in all the cases. The PCR bands of T antigen, VP and agnoprotein were confirmed by the specific probes in Southern blot analysis, respectively. The positive rate of JCV $\mathrm{T}$ antigen was higher in paraffin-embedded gastrointestinal carcinomas than adjacent NNM by nested-PCR followed by 
Table I. JCV existence in lung samples by nested PCR followed by Southern blot targeting T antigen.

\begin{tabular}{|c|c|c|c|c|c|c|c|}
\hline \multirow[t]{2}{*}{ Group } & \multirow[t]{2}{*}{ No. } & \multicolumn{2}{|c|}{$\mathrm{T}$ antigen } & \multicolumn{2}{|c|}{ VP } & \multicolumn{2}{|c|}{ Agno } \\
\hline & & + & $\mathrm{PR}(\%)$ & + & PR $(\%)$ & + & PR (\%) \\
\hline \multicolumn{8}{|l|}{ Frozen } \\
\hline Non-neoplastic mucosa & 40 & 4 & 10.0 & 1 & 2.5 & 3 & 7.5 \\
\hline Carcinoma & 40 & 6 & 15.0 & 3 & 7.5 & 4 & 10.0 \\
\hline \multicolumn{8}{|l|}{ Paraffin-embedded } \\
\hline Non-neoplastic mucosa & 65 & 11 & 16.9 & 11 & 16.9 & 16 & 24.6 \\
\hline Carcinoma & 83 & 29 & $34.9^{\mathrm{a}}$ & 22 & 26.5 & 16 & 19.2 \\
\hline
\end{tabular}

${ }^{\mathrm{a} C}$ Compared with non-neoplastic mucosa, $\mathrm{P}<0.05$. VP, viral protein; Agno, agnoprotein.
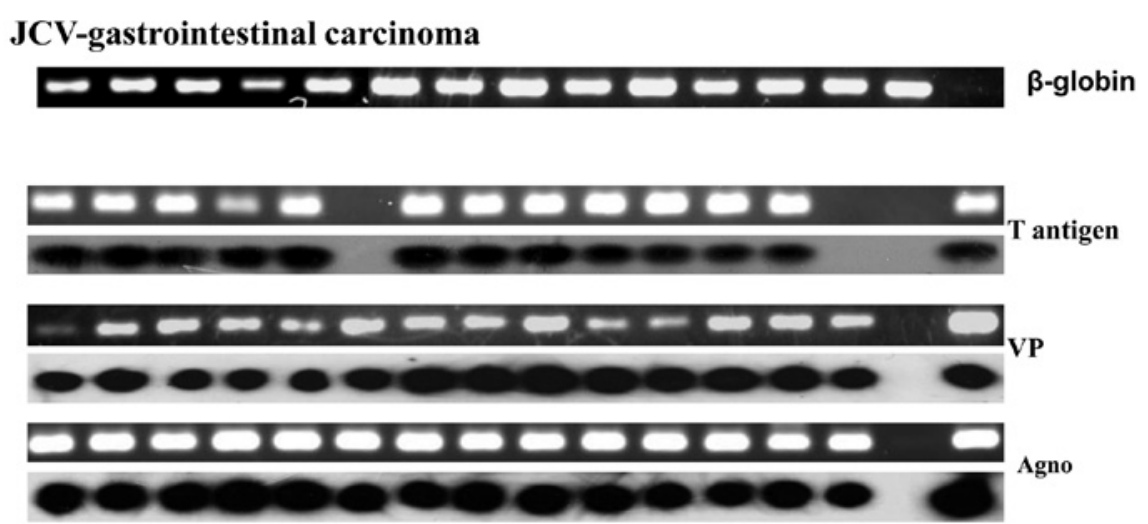

Figure 2. Detection of $\beta$-globin and T antigen, VP and agnoprotein in gastrointestinal carcinomas. $\beta$-globin was positive in all cases of lung carcinomas. $\mathrm{T}$ antigen was positive in some carcinoma cases by the nested PCR and Southern blot. PC, positive control; Neg, negative control.

Southern blot analysis (36.9 vs. 16.9\%, P<0.05) (Fig. 2 and Table I). However, no difference was observed in other viral oncogenes, even in paraffin-embedded or frozen samples. Immunohistochemically, $\mathrm{T}$ antigen was detectable in $9.6 \%$ $(13 / 135)$ of carcinoma cases, higher than its positive rate in NNM $(0.8 \%, 1 / 126, \mathrm{P}<0.01)$. There was genomic JCV DNA detected in these T-antigen-positive cases. The genomic JCV DNA existence or its $\mathrm{T}$ antigen expression was not correlated with clinicopathological parameters of gastrointestinal carcinomas $(\mathrm{P}>0.05)$, including age, gender, tumor size, histological types, lymph node metastasis, expression of ki-67, caspase-3, p53, Rb and $\beta$-catenin.

\section{Discussion}

In 1994, Theodoropoulos et al (30) for the first time employed real-time PCR successfully to detect JCV in colonic cancer and adjacent non-cancerous mucosa. At the same time, Schatzl et al (31) also began to examine the JCV in the brain and kidney tissue of PML using nested-PCR. In the present study, we for the first time examined the oncogenic role of genomic JCV DNA existence and its $\mathrm{T}$ antigen expression in Chinese gastrointestinal carcinoma and found that the positive rates were higher in carcinoma than that in matched NNM. In our previous study, it was found that JCV T antigen existence or copies were closely linked to the lung, tongue, pharyngeal and gastric carcinogenesis $(10,14,15,20)$. Hori et al (9) reported that $\mathrm{T}$ antigen was detected in 6 of 23 colorectal cancer cases $(26.1 \%)$ and 1 of 21 adenomas $(4.8 \%)$, but none of the 20 samples of normal colonic mucosa. These findings indicated that JCV $\mathrm{T}$ antigen may be involved in the malignant transformation of epithelium as evidenced by our transgenic lens tumor induced by $\mathrm{T}$ antigen, although we failed to establish the animal model of gastric tumor induced by the JCV T antigen (28).

Furthermore, previous studies have demonstrated the presence of replicating JCV DNA in B lymphocytes from peripheral blood, tonsils and spleen. Our previous study showed JCV T antigen in the nuclei of tonsil lymphocytes by in situ PCR (20), in line with virus persistence in a quiescent state in lymphoid tissue during latency and infection of other cells upon immune suppression (32). Detection of viral gene products in renal tubules and excretion of JC virions in the urine suggest JCV persistence in the kidney (33). In the present study, JCV DNA was detectable in gastrointestinal carcinoma. Earlier surveys of raw sewage from urban areas have shown the detection of JC viral particles in sewage samples from widely divergent areas (27), and the presence of JCV DNA sequences in the upper human gastrointestinal tract (17), suggesting a potential re-entry of JCV and/or viral DNA into the human digestive tracts through the intake of virus-contaminated water and food. 
The JCV T antigen shares more than 70\% homology with the SV40 T antigen, particularly in the N-terminus. Based on SV40 studies, the N-terminal domain serves multiple functions, including regulation of DNA replication, protein stability and cell immortalization (34). The protein region encoded by the large $\mathrm{T} / \mathrm{small} \mathrm{t}$ common exon is crucial in the control of the cell cycle by interacting with key cell proteins such as $\mathrm{pRb}$ and $\mathrm{Rb}$ family members including p107 and p130 (1-5). $\mathrm{T}$ antigen may inhibit cellular apoptosis by binding to the AP2 site of BAG3 and subsequently downregulate BAG3 promoter activity. In addition, $\mathrm{T}$ antigen binds $\beta \operatorname{TrCP} 1 / 2$ and disrupts further proteasomal degradation of $\beta$-catenin $(23,24)$. Therefore, we compared the JCV T antigen with the expression of ki-67, caspase-3, p53, Rb and $\beta$-catenin. However, no significant correlation has been found, possibly due to the lower rates of JCV T antigen in Chinese patients with gastrointestinal carcinomas. By contrast, it was documented that the lung carcinomas with high copy numbers for the virus were closely associated with high proliferation and downregulation of cell adhesion mediated by $\beta$-catenin (20).

In the present study, we employed nested-PCR to screen the JCV genes due to its low number of copies in human tissue. Since there is some homology between polyomaviruses SV40, BK and JC virus (4), a specific probe for JCV $T$ antigen was used to ensure the reality of these amplicons in the Southern blot analysis. Additionally, we used the anti-SV40 T antigen antibody to detect the JCV T antigen with a positive control of transgenic lens tumor-induced JCV T antigen (data not shown). To avoid false positivity, we evaluated the $\mathrm{T}$ antigen immunoreactivity in combination with nested-PCR followed by Southern blotting. Notably, JCV T antigen was higher in paraffin-embedded samples in line with our report, although the JCV T antigen copies were higher in frozen samples than those in paraffin-embedded ones (15).

In conclusion, the $\mathrm{T}$ antigen of JCV may contribute to gastrointestinal carcinogenesis and the gastrointestinal tract may lead to JCV infection. Possible molecular mechanisms of oncogenesis of the JCV T antigen in gastrointestinal carcinogenesis and the reasons for high detection rates of JCV genes should be elucidated in the future.

\section{Acknowledgements}

This study was supported by the Shenyang Outstanding Talent Foundation of China, Liaoning BaiQianWan Talents Program, Scientific and Technological Projects for Overseas Returned persons, Ministry of Personnel; Shenyang Science and Technology Grant (1091175-1-00); Scientific Research Foundation for the Returned Overseas Chinese Scholars.

\section{References}

1. Reiss K and Khalili K: Viruses and cancer: lessons from the human polyomavirus, JCV. Oncogene 22: 6517-6523, 2003.

2. Frisque RJ, Bream GL and Cannella MT: Human polyomavirus JC virus genome. J Virol 51: 458-469, 1984.

3. Zheng HC, Yan L, Cui L, Guan YF and Takano Y: Mapping the history and current situation of research on John Cunningham virus - a bibliometric analysis. BMC Infect Dis 9: 28, 2009.

4. White MK and Khalili K: Expression of JC virus regulatory proteins in human cancer: potential mechanisms for tumourigenesis. Eur J Cancer 41: 2537-2548, 2005.
5. White MK and Khalili K: Polyomaviruses and human cancer: molecular mechanisms underlying patterns of tumorigenesis. Virology 324: 1-16, 2004.

6. Khalili K, Gordon J and White MK: The polyomavirus, JCV and its involvement in human disease. Adv Exp Med Biol 577: 274-287, 2006.

7. Neel JV: The Colonel Harlan D. Sanders Award Address for 1998: JC virus and its possible role in oncogenesis. Am J Med Genet 83: 152-156, 1999.

8. Gordon J, Del Valle L, Otte J and Khalili K: Pituitary neoplasia induced by expression of human neurotropic polyomavirus, JCV, early genome in transgenic mice. Oncogene 19: 4840-4846, 2000.

9. Hori R, Murai Y, Tsuneyama K, Abdel-Aziz HO, Nomoto K, Takahashi H, Cheng CM, Kuchina T, Harman BV and Takano Y: Detection of JC virus DNA sequences in colorectal cancers in Japan. Virchow Arch 447: 723-730, 2005.

10. Zheng Y, Xia P, Zheng HC, Takahashi H, Masuda S and Takano Y: The screening of viral risk factors in tongue and pharyngolaryngeal squamous carcinoma. Anticancer Res 30: $1233-1238,2010$

11. Del Valle L, White MK, Enam S, Oviedo SP, Bromer MQ, Thomas RM, Parkman HP and Khalili K: Detection of JC virus DNA sequences and expression of viral $\mathrm{T}$ antigen and agnoprotein in esophageal carcinoma. Cancer 103: 516-527, 2005.

12. Enam S, Del Valle L, Lara C, Gan DD, Ortiz-Hidalgo C, Palazzo JP and Khalili K: Association of human polyomavirus JCV with colon cancer: evidence for interaction of viral T-antigen and beta-catenin. Cancer Res 62: 7093-7101, 2002.

13. Zambrano A, Kalantari M, Simoneau A, Jensen JL and Villarreal LP: Detection of human polyomaviruses and papillomaviruses in prostatic tissue reveals the prostate as a habitat for multiple viral infections. Prostate 53: 263-276, 2002.

14. Kutsuna T, Zheng H, Abdel-Aziz HO, Murai Y, Tsuneyama K, Furuta I and Takano Y: High JC virus load in tongue carcinomas may be a risk factor for tongue tumorigenesis. Virchows Arch 452: 405-410, 2008.

15. Murai Y, Zheng HC, Abdel Aziz HO, Mei H, Kutsuna T, Nakanishi Y, Tsuneyama K and Takano Y: High JC virus load in gastric cancer and adjacent non-cancerous mucosa. Cancer Sci 98: 25-31, 2007.

16. Link A, Shin SK, Nagasaka T, Balaguer F, Koi M, Jung B, Boland CR and Goel A: JC virus mediates invasion and migration in colorectal metastasis. PLoS One 4: e8146, 2009.

17. Ricciardiello L, Laghi L, Ramamirtham P, Chang CL, Chang DK, Randolph AE and Boland CR: JC virus DNA sequences are frequently present in the human upper and lower gastrointestinal tract. Gastroenterology 119: 1228-1235, 2000.

18. Niv Y, Goel A and Boland CR: JC virus and colorectal cancer: a possible trigger in the chromosomal instability pathways. Curr Opin Gastroenterol 21: 85-89, 2005.

19. Shin SK, Li MS, Fuerst F, Hotchkiss E, Meyer R, Kim IT, Goel A and Boland CR: Oncogenic T-antigen of JC virus is present frequently in human gastric cancers. Cancer 107: 481-488, 2006.

20. Zheng H, Abdel Aziz HO, Nakanishi Y, Masuda S, Saito H, Tsuneyama K and Takano Y: Oncogenic role of JC virus in lung cancer. J Pathol 212: 306-315, 2007.

21. Ramamoorthy S, Devaraj B, Miyai K, Luo L, Liu YT, Boland CR, Goel A and Carethers JM: John Cunningham virus T-antigen expression in anal carcinoma. Cancer (Epub ahead of print) in press, 2010.

22. Wang JP, Zhang MY, Xu XY, Wang W, Xia P, Zheng ZH, Wang LZ and Takano Y: The establishment of transgenic mouse model of lens epithelial tumors induced by JC Virus T Antigen. J Chin Med U 40: 27-29, 2011.

23. Basile A, Darbinian N, Kaminski R, White MK, Gentilella A, Turco MC and Khalili K: Evidence for modulation of BAG3 by polyomavirus JC early protein. J Gen Virol 90: 1629-1640, 2009.

24. Reviriego-Mendoza MM and Frisque RJ: Interaction and co-localization of JC virus large T antigen and the F-box protein $\beta$-transducin-repeat containing protein. Virology 410: 119-128. 2011.

25. Kelley JR and Duggan JM: Gastric cancer epidemiology and risk factors. J Clin Epidemiol 56: 1-9, 2003.

26. American Cancer Society: Colorectal cancer facts and figures. 3rd edition. American Cancer Society, 2009.

27. Calgua B, Barardi CR, Bofill-Mas S, Rodriguez-Manzano J and Girones R: Detection and quantitation of infectious human adenoviruses and JC polyomaviruses in water by immunofluorescence assay. J Virol Methods 171: 1-7, 2011. 
28. Xia P, Xu XY, Jia BP, Wang W, Guan YF, Takano Y and Zheng HC: The construction and expression confirmation of $\mathrm{JC}$ virus $\mathrm{T}$ antigen expression plasmid in gastric mucosa. J Chin Med U 39: 18-21, 2010.

29. Kumada T, Tsuneyama K, Hatta H, Ishizawa S and Takano Y: Improved 1-h rapid immunostaining method using intermittent microwave irradiation: practicability based on 5 years application in Toyama Medical and Pharmaceutical University Hospital. Mod Pathol 17: 1141-1149, 2004.

30. Theodoropoulos G, Panoussopoulos D, Papaconstantinou I, Gazouli M, Perdiki M, Bramis J and Lazaris ACh: Assessment of JC polyoma virus in colon neoplasms. Dis Colon Rectum 48: 86-91, 2005.

31. Schätzl HM, Sieger E, Jäger G, Nitschko H, Bader L, Ruckdeschel G and Jäger G: Detection by PCR of human polyomaviruses $\mathrm{BK}$ and $\mathrm{JC}$ in immunocompromised individuals and partial sequencing of control regions. J Med Virol 42: 138-145, 1994.
32. Monaco MC, Jensen PN, Hou J, Durham LC and Major EO: Detection of JC virus DNA in human tonsil tissue: evidence for site of initial viral infection. J Virol 72: 9918-9923, 1998.

33. Boldorini R, Veggiani C, Barco D and Monga G: Kidney and urinary tract polyomavirus infection and distribution. Molecular biology investigation of 10 consecutive autopsies. Arch Pathol Lab Med 129: 69-73, 2005.

34. Cozen SD and Cole CN: The three transforming regions of SV40 $\mathrm{T}$ antigens are required for immortalization of primary mouse embryo fibroblasts. Oncogene 11: 2295-2302, 1995. 